\title{
STUDY ON MODEL FOR CUTTING FORCE WHEN MILLING SCM440 STEEL
}

\author{
Nguyen Van Thien \\ Faculty of Mechanical Engineering ${ }^{l}$ \\ Do Duc Trung $\bowtie$ \\ Faculty of Mechanical Engineering ${ }^{l}$ \\ doductrung@haui.edu.vn \\ ${ }^{1}$ Hanoi University of Industry \\ 298 Cau Dien str., Bac Tu Liem District, Hanoi, Vietnam, 100000
}

$\triangle$ Corresponding author

\begin{abstract}
This article presents empirical study results when milling SCM440 steel. The cutting insert to be used was a TiN coated cutting insert with tool tip radius of $0.5 \mathrm{~mm}$. Experimental process was carried out with 18 experiments according to Box-Behnken matrix, in which cutting speed, feed rate and cutting depth were selected as the input parameters of each experiment. In addition, cutting force was selected as the output parameter. Analysis of experimental results has determined the influence of the input parameters as well as the interaction between them on the output parameters. From the experimental results, a regression model showing the relationship between cutting force and input parameters was built. Box-Cox and Johnson data transformations were applied to construct two other models of cutting force. These three regression models were used to predict cutting force and compare with experimental results. Using parameters including coefficient of determination $(R-S q)$, adjusted coefficient of determination $(R-S q(a d j))$ and percentage mean absolute error $(\% M A E)$ between the results predicted by the models and the experimental results are the criteria to compare the accuracy of the cutting force models. The results have determined that the two models using two data transformations have higher accuracy than model not using two data transformations. A comparison of the model using the Box-Cox transformation and the model using the Johnson transformation was made with a $t$-test. The results confirmed that these two models have equal accuracy. Finally, the development direction for the next study is mentioned in this article.
\end{abstract}

Keywords: SCM440 steel milling, Cutting force, Box-Cox transformation, Johnson transformation, t-test.

DOI: $10.21303 / 2461-4262.2021 .001743$

\section{Introduction}

Milling method is widely used in mechanical machining by its high machining productivity. Thanks to the advancement of cutting tool making technology as well as the experimental equipment, the precision of the milling method is also improved. Hence, milling has also been chosen as the final machining method for a variety of machining surfaces in many cases. The cutting force during milling process not only affects the machining accuracy and the durability of the cutting tools, but also works on the energy consumption of the machining process. With the expectation that the cutting force during milling process is of small value, many studies have been done to build the cutting force model. The cutting force model is the basis for predicting cutting force during machining as well as the basis for selecting machining parameters to ensure cutting force has small value. Study on building cutting force model by theoretical method has been done by many authors, such as: when using face milling cutter [1, 2], when using ball end milling [3-5], when using cylindrical end mill [6]. However, when building cutting force models according to these studies, the number of calculations is very large, and there is still a need for more experimental studies to determine some parameters, such as coefficient of friction and shear force coefficient. Therefore, this method is time consuming and costly.

Another simple study direction to build cutting force model which has been done by many authors is based on the results of the experimental process. In those studies, a relationship between cutting force and machining parameters has been established. The cutting force model shows the relationship between the cutting force with the trochoid step and trochoidal milling when milling EN X38CrMoV5-1 material with UNIFR41010xR1 cutting tool [7]. Relationship between cutting force with spindle speed, feed rate, axial depth of cut, radial depth of cut, and percentage of silicon 
carbide in the workpiece material when milling LM6/SiCp with a hard alloy cutting tool has been established in document No. [8]. The relationship between cutting force with cutting speed and feed rate has been established when milling UNS A92024-T3 (Al-Cu) material with WC-10Co cutting tool material [9]. In document No. [10], it has built a relationship between cutting force with cutting speed, feed rate and cutting depth when using a titanium cutting tool to mill four different materials including C45 steel, aluminium alloy (7178), grey cast iron, and titanium (purity $99 \%$ ). Document No. [11] has established a relationship between cutting force with step over and feed rate when using a hard alloy cutting tool to milling A1 7075-T651 aluminum alloy. The relationship between the cutting force and cutting speed, feed rate, cutting depth and kinematical direction of cut (conventional or climb milling) when using Sumitomo AXMT123504PEERG cutting insert for milling high strength structural steel (S960QL) was performed in document No. [12]. In document No. [13], it presented the relationship between cutting force with cutting speed and feed rate when using TiN coated milling cutter to milling Ti-6Al-4AV aluminum alloy. The relationship between cutting force and cutting speed, feed rate and cutting depth when milling medium carbon steel with TiN coated cutting tool has been presented in study No. [14]. Document No. [15] has built the relationship between cutting force and cutting speed, feed rate and cutting depth when using TiN coated milling cutter to milling $1 \mathrm{Cr} 13$ martensitic stainless steel.

By some empirical study on building cutting force model mentioned above, they show that cutting speed, feed rate and cutting depth are often selected as input parameters of experimental study. This is also easily explained because the adjustment of these parameters will be more easily done by the worker than by other parameters (vibration and stability of system, etc.).

SCM440 steel is a steel with high deformation resistance and wear resistance. This steel is often used to fabricate components with heavy loads, wear resistance and impact such as gears, drive shafts. This steel is also commonly used to manufacture injection moulding. Study on material type machining technology has been carried out by a number of authors, such as: surveying the flatness of the tool when milling [16], determining the optimal value of cutting parameters when turning to ensure minimum value of surface roughness [17], determining optimal cutting parameters when turning to ensure minimum value of surface roughness and tool wear [18], study on drilling technology this material when using a number of different cooling methods [19]. Study on milling equivalent steels of this steel has also been carried out by a number of studies, such as: building surface roughness models and determining the optimal value of cutting parameters to ensure that surface roughness has the smallest value when milling with TiAlN+TiN coated cutting tool [20], studying the efficiency of using coolant when milling with TiAlN coated cutting tools [21], surveying on surface roughness when milling with cutting tools made of CBN [22], comparing cutting force, tool wear and surface roughness when milling with 5 types of cutting tools coated with different materials (WC-Co-TiC, $\mathrm{Al}_{2} \mathrm{O}_{3}-\mathrm{TiC}$, Ti(C, N), Ti(C, N)-WC-Mo $\mathrm{C}_{2}-\mathrm{Ni}-\mathrm{Co}$, and $\left.\mathrm{Ti}(\mathrm{C}, \mathrm{N})-\mathrm{WC}-\mathrm{Mo}_{2} \mathrm{C}-\mathrm{Co}\right)[23]$. This study has determined that out of five types of cutting tool materials, $\mathrm{Ti}(\mathrm{C}, \mathrm{N})$ coated cutting tools have the highest efficiency. However, according to the authors of this article, there has been no published study on building cutting force models when milling SCM440 steel as well as steel equivalent to this type of steel up to now.

With the arguments presented above, this study will conduct experiments on steel milling SCM440 process. The aim of this research is to build a cutting force model that shows the relationship between cutting force and parameters of cutting parameters. Study for improving the accuracy of the model has also been performed and that is the main aim of this research.

\section{Materials and methods}

SCM440 steel was selected as the experimental material in this study. The experimental steel sample is a cube with sides equal to $45 \mathrm{~mm}$. In Table 1, the chemical composition of steel when spectrally analyzed is shown.

The composition of the elements in Table 1 is obtained by analyzing the steel sample on a spectrophotometer.

Experiments were performed on a 5-axis CNC milling machine with symbol of DMU 50 ECOLINE. The machine uses SINUMERIK S840DSB operating system. Cutting tool 
used during the experiment was a cutting insert coated with $\mathrm{Ti}(\mathrm{C}, \mathrm{N})$. The insert has the symbol of R390-11T308M. Some geometric parameters of the cutting insert are as follows: tip radius is $0.8 \mathrm{~mm}$, relief angle is $6^{\circ}$, inclination angle is $-6^{\circ}$, cutting edge angle is $75^{\circ}$, and rake angle of ceramic tool is $-6^{\circ}$. The body of the cutting tool is $14 \mathrm{~mm}$ in diameter, on which two symmetrical cut insert are attached. To eliminate the effect of tool wear on the output parameters, each cutting insert is used for only one experiment.

Table 1

Chemical composition of SCM440 steel

\begin{tabular}{cccccccc}
\hline Element & $\mathbf{C}$ & $\mathbf{S i}$ & $\mathbf{M n}$ & $\mathbf{P}$ & $\mathbf{S}$ & $\mathbf{C r}$ & Mo \\
\hline$[\%]$ & 0.41 & 0.33 & 0.78 & $<0.03$ & $<0.03$ & 1.12 & 0.25
\end{tabular}

The cutting force components of $F_{x}, F_{y}$ and $F_{z}$ in the $x, y$ and $z$ directions were measured by Kistler's force sensor with sensor symbol of 9139AA. Use cables to connect the load cell and the data processor, then the measured signal is processed by software in the computer. Fig. 1 shows the details of the experimental system.

Cutting force at each experiment is determined by the following (1):

$$
F_{c}=\sqrt{F_{x}^{2}+F_{y}^{2}+F_{z}^{2}} .
$$

$F_{x}, F_{y}, F_{z}$ are respectively the force components in the three directions of the coordinate system.

Experiments were performed according to Box-Behnken experimental matrix, in which cutting speed, feed rate and cutting depth were selected as the input parameters of the experimental process. In this matrix form, each input parameter will have three values corresponding to coding levels of $-1,0$ and 1 [24]. The values of selected input parameters according to the cutting tool manufacturer's recommendation and by study No. [25] are presented in Table 2.

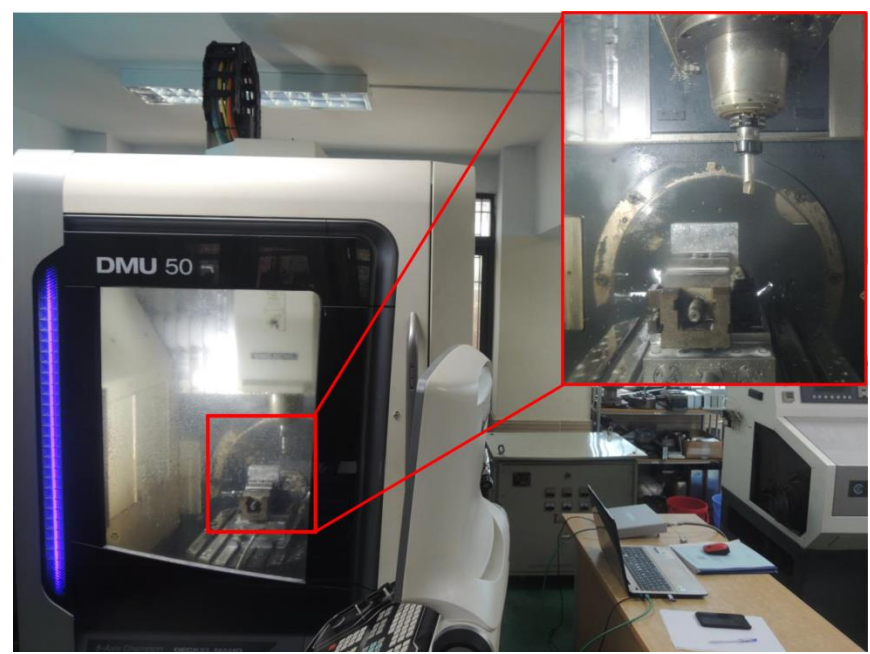

Fig. 1. Experimental system

Table 2

Input parameters

\begin{tabular}{ccccccc}
\hline \multirow{2}{*}{ Parameter } & \multirow{2}{*}{ Unit } & \multirow{2}{*}{ Code symbol } & \multirow{2}{*}{ Actual symbol } & \multicolumn{3}{c}{ Value at levels } \\
\hline Cutting speed & $\mathrm{m} / \mathrm{min}$ & $x_{1}$ & $v_{c}$ & $-\mathbf{1}$ & $\mathbf{0}$ & $\mathbf{1}$ \\
Feed rate & $\mathrm{mm} /$ tooth & $x_{2}$ & $f_{z}$ & 0.1 & 200 & 260 \\
Depth of cut & $\mathrm{mm}$ & $x_{3}$ & $a_{p}$ & 0.28 & 0.2 & 0.3 \\
\end{tabular}


The experimental matrix was designed in Box-Behnken format with 15 experiments, including 6 experiments at the central level, as shown in Table 3.

\section{Results and discussion}

Experiments were carried out in the order shown in Table $\mathbf{3}$ and cutting force values at each experiment were also included in this table.

Table 3

Experimental matrices and results

\begin{tabular}{|c|c|c|c|c|c|c|c|}
\hline \multirow{2}{*}{ No. } & \multicolumn{3}{|c|}{ Code value } & \multicolumn{3}{|c|}{ Actual value } & \multirow{2}{*}{$\begin{array}{c}\text { Cutting force } \\
F_{c}(\mathrm{~N})\end{array}$} \\
\hline & $x_{1}$ & $x_{2}$ & $x_{3}$ & $v_{c}(\mathrm{~m} / \mathrm{min})$ & $f_{z}(\mathrm{~mm} /$ tooth $)$ & $a_{p}(\mathrm{~mm})$ & \\
\hline 1 & -1 & 0 & 1 & 140 & 0.2 & 0.52 & 130.56 \\
\hline 2 & 0 & 0 & 0 & 200 & 0.2 & 0.4 & 110.08 \\
\hline 3 & 1 & 1 & 0 & 260 & 0.3 & 0.4 & 156.16 \\
\hline 4 & 0 & 0 & 0 & 200 & 0.2 & 0.4 & 112.64 \\
\hline 5 & 1 & 0 & -1 & 260 & 0.2 & 0.28 & 85.76 \\
\hline 6 & 0 & 1 & -1 & 200 & 0.3 & 0.28 & 240.64 \\
\hline 7 & 0 & 1 & 1 & 200 & 0.3 & 0.52 & 258.56 \\
\hline 8 & -1 & 1 & 0 & 140 & 0.3 & 0.4 & 152.32 \\
\hline 9 & 0 & 0 & 0 & 200 & 0.2 & 0.4 & 111.36 \\
\hline 10 & 0 & 0 & 0 & 200 & 0.2 & 0.4 & 104.96 \\
\hline 11 & 1 & -1 & 0 & 260 & 0.1 & 0.4 & 92.16 \\
\hline 12 & -1 & 0 & -1 & 140 & 0.2 & 0.28 & 104.96 \\
\hline 13 & -1 & -1 & 0 & 140 & 0.1 & 0.4 & 106.24 \\
\hline 14 & 0 & -1 & 1 & 200 & 0.1 & 0.52 & 92.16 \\
\hline 15 & 1 & 0 & 1 & 260 & 0.2 & 0.52 & 79.36 \\
\hline 16 & 0 & 0 & 0 & 200 & 0.2 & 0.4 & 104.96 \\
\hline 17 & 0 & 0 & 0 & 200 & 0.2 & 0.4 & 119.04 \\
\hline 18 & 0 & -1 & -1 & 200 & 0.1 & 0.28 & 88.32 \\
\hline
\end{tabular}

Three cutting force components $\left(F_{x}, F_{y}\right.$, and $\left.F_{z}\right)$ are measured during the time the cutter enters the workpiece, the cutting force value $\left(F_{c}\right)$ at each experiment is calculated according to (1).

Minitab 16 statistical software is used to analyze experimental results in Table 3. Pareto diagram of the influence of the input parameters on the cutting force is shown in Fig. 2.

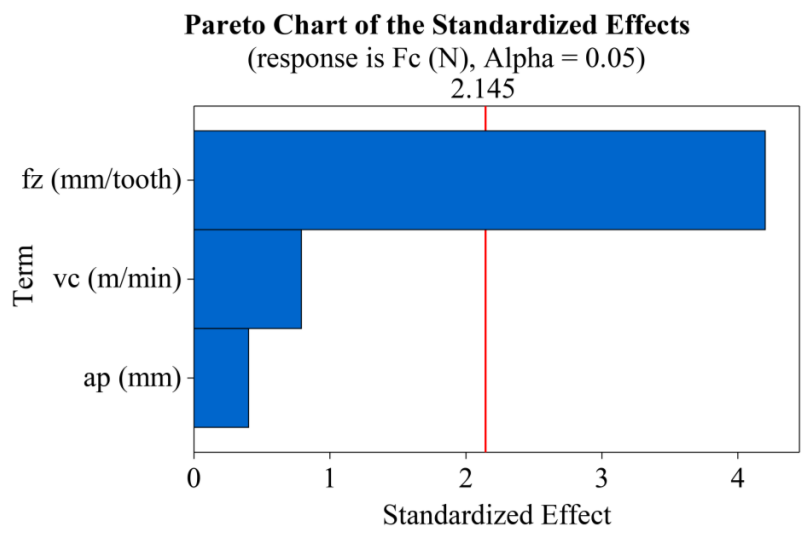

Fig. 2. Pareto plot for $F_{c}$

With the significance level chosen by $0.05(\alpha=0.05)$, Fig. 2 shows that: feed rate is the only parameter whose Pareto plot surpasses the chart bounding line (red line) among the three input 
parameters. Thus, feed rate is only parameter that has a significant influence on the cutting force. This is also easy to explain because changing the feed rate changes the surface response of the part to the insert. Therefore, the cutting force components will change in all directions $\left(F_{x}, F_{y}\right.$, and $\left.F_{z}\right)$, leading to a much change in cutting force $F_{c}$. Cutting speed and cutting depth have a negligible effect on cutting force. However, the effect of the cutting speed on the cutting force is greater than the effect of the cutting depth if they are considered in detail.

The Minitab 16 statistical software was again used to determine the influence of the interaction between the input parameters on the cutting force, the results are shown in Fig. 3.

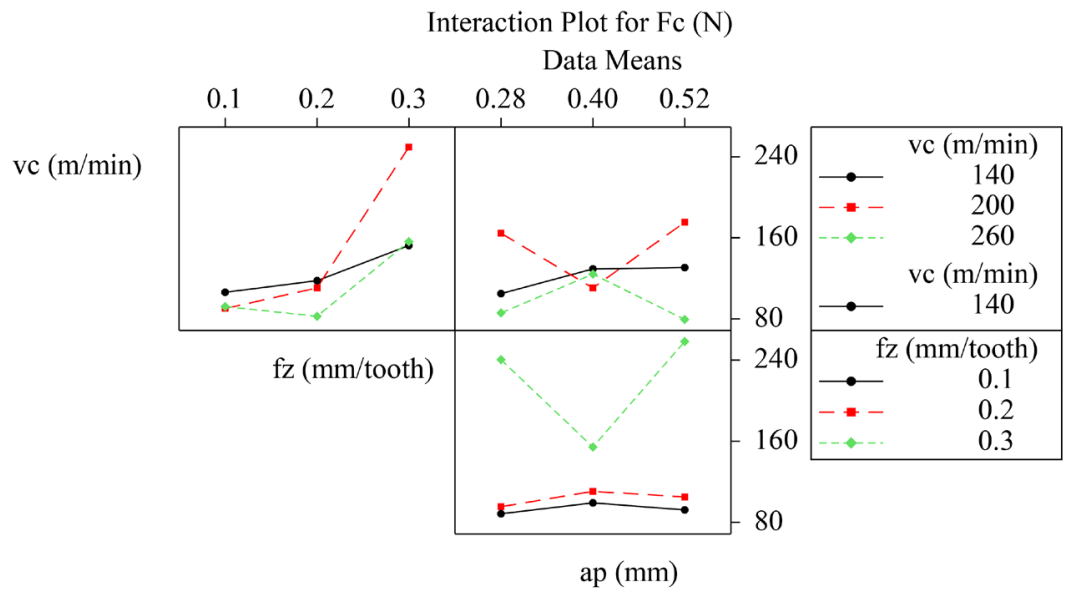

Fig. 3. Interaction effects plot for $F_{c}$

Form Fig. 3, it shows that:

- when cutting speed is $140 \mathrm{~m} / \mathrm{min}$, increasing the value of the feed rate will cause the cutting force to increase but at a slow speed. When the cutting speed is $200 \mathrm{~m} / \mathrm{min}$, if feed rate increases from $0.1 \mathrm{~mm} /$ tooth to $0.2 \mathrm{~mm} /$ tooth, cutting force will increase slowly, but the cutting force increases rapidly if the feed rate continues to increase. In the case the cutting speed is $260 \mathrm{~m} / \mathrm{min}$, cutting force will decrease when the feed rate increases from $0.1 \mathrm{~mm} /$ tooth to $0.2 \mathrm{~mm} /$ tooth, but cutting force will increase if the feed rate increases from $0.2 \mathrm{~mm} /$ tooth to $0.3 \mathrm{~mm} /$ tooth;

- when cutting speed is $140 \mathrm{~m} / \mathrm{min}$, if cutting depth increases, cutting force will increase slowly. When cutting speed is $200 \mathrm{~m} / \mathrm{min}$, cutting force will decrease when cutting depth increases from $0.28 \mathrm{~mm}$ to $0.4 \mathrm{~mm}$, but cutting force will increase if cutting depth continues to increase. In the case cutting speed is $260 \mathrm{~m} / \mathrm{min}$, cutting force will increase when cutting depth increases from $0.28 \mathrm{~mm}$ to $0.4 \mathrm{~mm}$, but cutting force will decrease if cutting depth of continues to increase;

- when feed rate is $0.1 \mathrm{~mm} /$ tooth and $0.2 \mathrm{~mm} /$ tooth, cutting force is almost unchanged when cutting depth is changed. In the case feed rate is $0.3 \mathrm{~mm} /$ tooth, cutting force will decrease rapidly if cutting depth increases from $0.28 \mathrm{~mm}$ to $0.4 \mathrm{~mm}$, cutting force will increase rapidly if cutting depth increases from $0.4 \mathrm{~mm}$ to $0.52 \mathrm{~mm}$.

The above analysis shows that the influence of the input parameters on the cutting force is very complicated. These are phenomena that occur during the experiment, it is very difficult to explain by the theory of cutting process. Therefore, if only based on the experimental results, it will be difficult to choose the value of the input parameters to ensure that the cutting force is small. In this case, it is necessary to build a cutting force model showing the relationship between cutting force and input parameters. This relationship is the basis for determining the value of the input parameters to ensure the desired value of the output parameter.

From the data in Table 3, a regression model of cutting force has been built as shown in (2).

$$
\begin{gathered}
F_{c}=110.5067-10.0800 \cdot x_{1}+53.6000 \cdot x_{2}+5.1200 \cdot x_{3}-26.7733 \cdot x_{1}^{2}+42.9867 \cdot x_{2}^{2}+ \\
+16.4267 \cdot x_{3}^{2}+4.4800 \cdot x_{1} \cdot x_{2}-8.0000 \cdot x_{1} \cdot x_{3}+3.5200 \cdot x_{2} \cdot x_{3} .
\end{gathered}
$$


This model has $R-S q=0.8571$ and adjusted $R-S q(a d j)=0.6964$. The meanings of these values have been discussed in many documents No. [24, 26, 27]. The closer the values of these parameters are to 1 , the higher the accuracy of the model. The value of the coefficient determined is 0.8571 and it is possible to increase the value of these parameters by adding to the model higher order quantities of the input parameters $\left(x_{i}^{3}, x_{i}^{4}, \ldots, x_{i}^{n}\right)$ or considering the interaction affect between all three input parameters $\left(x_{1} \cdot x_{2} \cdot x_{3}\right)$. However, this action will make the model much more complex [24, 26, 27]. Value of adjusted coefficient of determination of 0.6964 shows that the change of cutting force is only determined by the change of the input parameters at $69.64 \%$. Therefore, problem here is how to increase the values of these two parameters $(R-S q$ and $R-S q(a d j))$ without adding any additional parameters to the model.

Box-Cox and Johnson data transformations are known as tools to convert non-distributed dataset according to the standard rule into distributed dataset according to the standard rule [27]. Box-Cox transformation has been successfully applied to improve the accuracy of surface roughness model when milling EN 353 steel [28], surface roughness model when milling AISI 1019 steel [29]. The Johnson transformation has also been successfully applied to improve the accuracy of surface roughness model when lathing 3X13 steel [30]. Both of these transformations have also been successfully applied to improve the accuracy of the surface roughness model when turning 9XC steel, which showed that the model using the Box-Cox transformation has higher accuracy than the model using the Johnson transformation [31]; surface roughness model when surface grinding of $65 \mathrm{G}$ steel, which also determined the model using Johnson transformation was more accurate than the model using the Box-Cox transformation [32]. In this study, these two transformations will be applied to improve the accuracy of the cutting force model when milling SCM440 steel.

From the data in Table 3, using statistical software Minitab 16 has determined the distribution law of cutting force as shown in Fig. 4 shows that the cutting force values (denoted by red dots) are distributed quite far from the standard line (straight line). On the other hand, $P$-value $<0.005$ is smaller than the significance level (significance level of $\alpha=0.05$ is often chosen). Thus, it can be confirmed that the dataset on cutting force is not distributed according to the standard rule. This is a necessary condition to perform data transformations [27].

Box-Cox transformation is performed by the following formula [27, 33]:

$$
\left[\begin{array}{l}
F_{c}^{\prime}=F_{c}^{\lambda} \text { when } \lambda \neq 0, \\
F_{c}^{\prime}=\ln \left(F_{c}\right) \text { when } \lambda=0 .
\end{array}\right.
$$

In which, $F_{c}^{\prime}$ is the value of cutting force after transformation, $F_{c}$ is value of cutting force in the experiment, $\lambda$ is the exponential transformation factor. Minitab statistical software was used to perform Box-Cox transformation for cutting force data in Table 3.

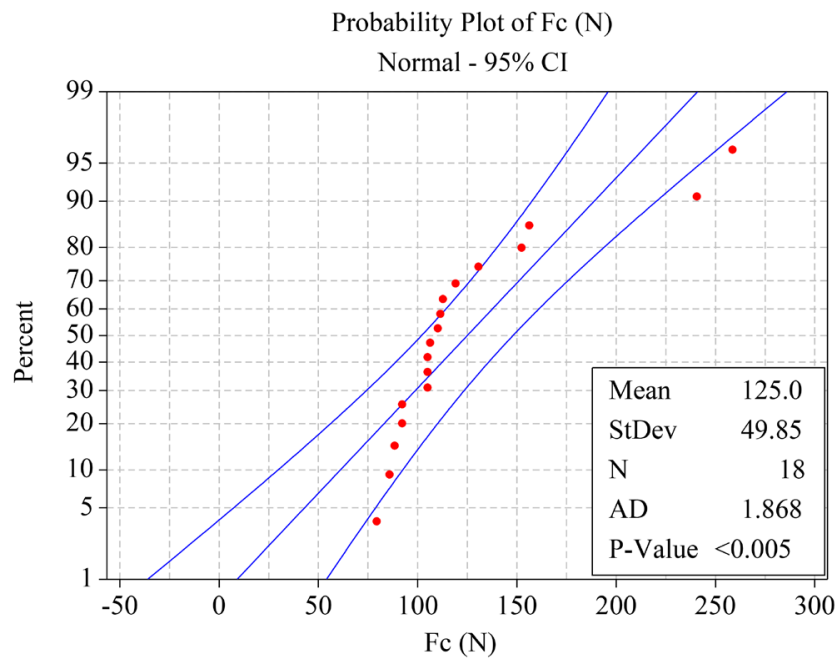

Fig. 4. Distribution law of cutting force during experiment 
Fig. 5 shows a graph of the Box-Cox transformation. From this figure, it shows that the coefficient $\lambda$ is equal to -2.00 . Cutting forces values in Table 3 after being converted Box-Cox are as shown in Table 4.

Box-Cox Plot of Fc (N)

Lower CL Upper CL

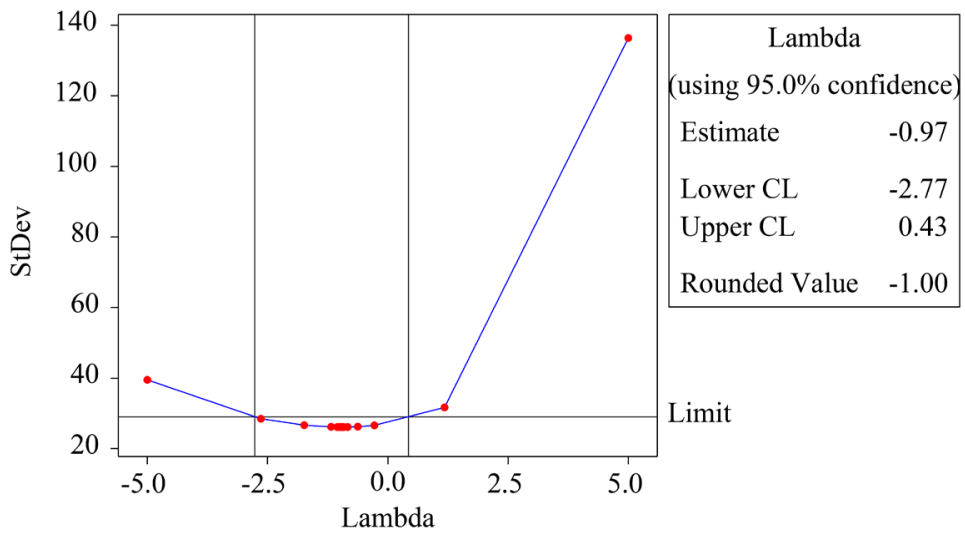

Fig. 5. Box-Cox transformation graph

Table 4

Value of cutting force before and after transformation

\begin{tabular}{cccc}
\hline \multirow{2}{*}{ No. } & \multicolumn{3}{c}{ Cutting force } \\
\cline { 2 - 4 } & Experiment (N) & Box-Cox transformation (dimensionless) & Johnson transformation (dimensionless) \\
\hline 1 & 130.56 & 0.0000587 & 0.6836988 \\
3 & 110.08 & 0.0000825 & 0.1429585 \\
4 & 156.16 & 0.0000410 & 1.1014878 \\
5 & 112.64 & 0.0000788 & 0.2287090 \\
6 & 85.76 & 0.0001360 & -1.3449952 \\
7 & 240.64 & 0.0000173 & 1.8458145 \\
8 & 258.56 & 0.0000150 & 1.9500000 \\
9 & 152.32 & 0.0000431 & 1.0491470 \\
10 & 111.36 & 0.0000806 & 0.1867316 \\
11 & 104.96 & 0.0000908 & -0.0533265 \\
12 & 92.16 & 0.0001177 & -0.7824216 \\
13 & 104.96 & 0.0000908 & -0.0533265 \\
14 & 106.24 & 0.0000886 & -0.0007049 \\
15 & 92.16 & 0.0001177 & -0.7824216 \\
16 & 79.36 & 0.0001588 & -1.9500000 \\
17 & 104.96 & 0.0000908 & -0.0533265 \\
18 & 119.04 & 0.0000706 & 0.4158884 \\
& 88.32 & 0.0001282 & -1.1042581
\end{tabular}

Fig. 6 shows the distribution rule of cutting force after the Box-Cox transformation. Fig. 6 shows that the cutting force values distributed around the standard line (straight line); on the other hand, $P$-value $=0.212$ is much larger than the significance level. Therefore, it is confirmed that the dataset of the cutting force after the Box-Cox transformation was distributed according to the standard rule [27].

From cutting force data after being transformed (Table 4) and value of $\lambda$, a new model of cutting force is built as shown in (4). This model has the coefficient of determination of 0.8824 and the adjusted coefficient of determination of 0.7500 : 


$$
F_{c}=\left[10^{-4} \cdot\left(\begin{array}{l}
0.8235+0.2154 \cdot x_{1}-0.4199 \cdot x_{2}-0.0276 \cdot x_{3}+0.1588 \cdot x_{1}^{2}- \\
-0.2562 \cdot x_{2}^{2}+0.1281 \cdot x_{3}^{2}-0.0781 \cdot x_{1} \cdot x_{2}+0.1373 \cdot x_{1} \cdot x_{3}+ \\
+0.0204 \cdot x_{2} \cdot x_{3}
\end{array}\right)\right]^{-\frac{1}{2}}
$$

Johnson transformation is applied to transform cutting force data in Table 3. Fig. 7 is the graph of transformation. Cutting force values after transformation are also included in Table 4.

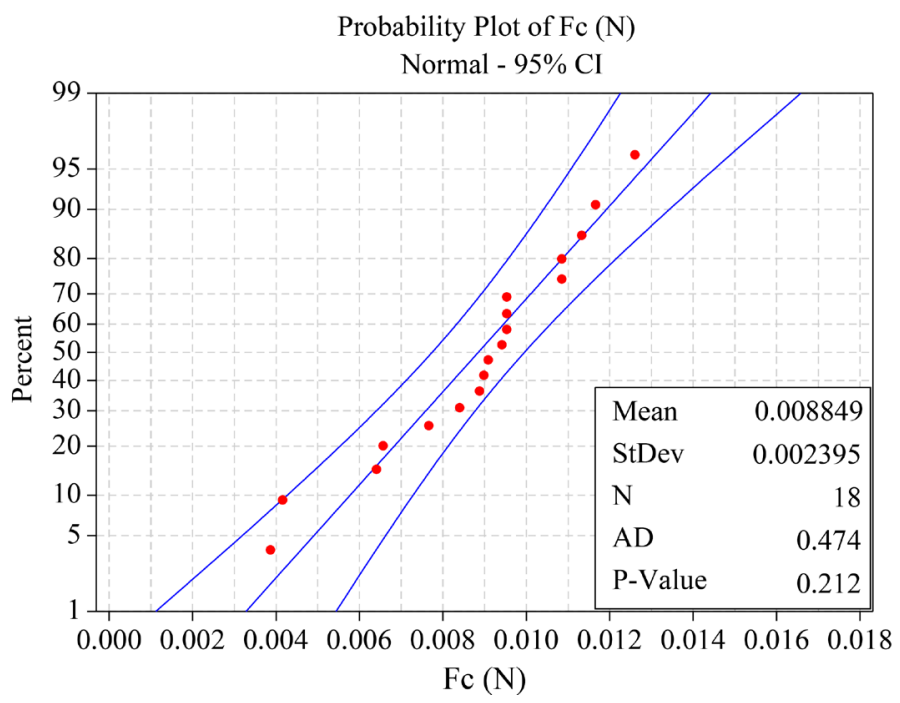

Fig. 6. Distribution rule of cutting force after Box-Cox transformation

Johnson Transformation for Fcl (N)

Probability Plot for Original Data

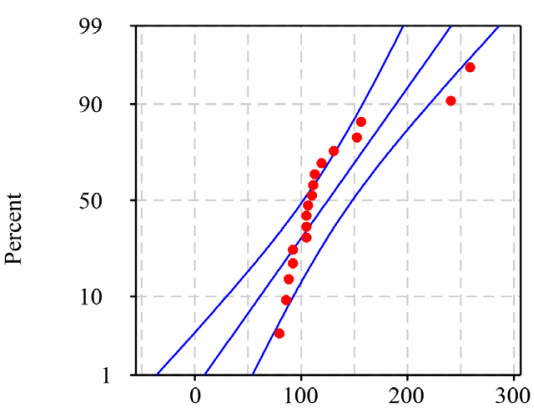

Probability Plot for Transformed Data

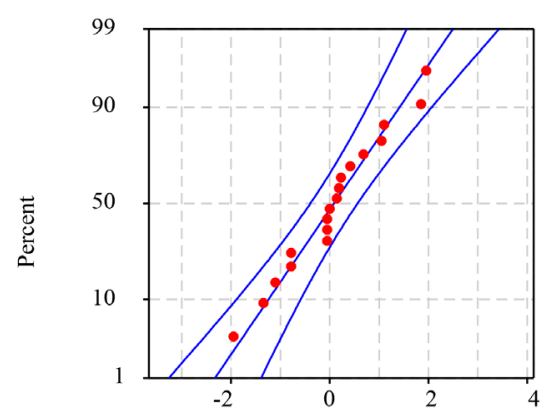

Select a Transformation

\begin{tabular}{|lr|}
\hline $\mathrm{N}$ & 18 \\
$\mathrm{AD}$ & 1.868 \\
$\mathrm{P}-$ Value & $<0.005$ \\
\hline
\end{tabular}

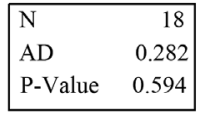

P-Value for Best Fit: 0.594044

$Z$ for Best Fit: 0.65

Best Transformation Type: SU

Transformation function equals

$-1.47845+0.961299 * A \sinh ((X-84.3881) / 9.85042)$

Fig. 7. Johnson transformation graph 
The upper left part of Fig. 7 shows the distribution rule of cutting force without transformation (as being analyzed above). The lower left portion of Fig. 7 shows the distribution rule of the cutting force after being transformed. Observing this figure shows that the cutting force values distributed very close to the standard line. This will also be more obvious when looking at the top right image. On the other hand, the $P$-value of 0.594 is much larger than the significance level. It confirms that the Johnson transformation has been done successfully [27]. In the lower right part of the figure shows the transformation formula, from which a cutting force model is built as shown in (5).

$$
\begin{gathered}
-1.47845+0.961299 \cdot \mathrm{A} \sinh \left[\left(F_{c}-84.3881\right) / 9.85042\right]= \\
=0.1446-0.5818 \cdot x_{1}+1.0770 \cdot x_{2}+0.0698 \cdot x_{3}-0.4731 \cdot x_{1}^{2}+ \\
+0.6704 \cdot x_{2}^{2}-0.3377 \cdot x_{3}^{2}+0.2085 \cdot x_{1} \cdot x_{2}-0.3355 \cdot x_{1} \cdot x_{3}-0.0544 \cdot x_{2} \cdot x_{3} .
\end{gathered}
$$

(5) is rewritten in the following form:

$$
F_{c}=84.3381+0.985042 \cdot \operatorname{Sinh}\left(\begin{array}{l}
1.6884-0.6052 \cdot x_{1}+1.1204 \cdot x_{2}+0.0726 \cdot x_{3}- \\
-0.4921 \cdot x_{1}^{2}+0.6974 \cdot x_{2}^{2}-0.3513 \cdot x_{3}^{2}+ \\
+0.2169 \cdot x_{1} \cdot x_{2}-0.3490 \cdot x_{1} \cdot x_{3}-0.0566 \cdot x_{2} \cdot x_{3}
\end{array}\right) .
$$

(6) has the coefficient of determination and adjusted coefficient of determination are 0.8686 and 0.7208 , respectively. In order to compare the three models of cutting force that were established above, in addition to coefficient of determination and adjustment coefficient of determination, percentage mean absolute error (\% MAE) between the cutting force value during experiment and the cutting force value predicted by these models should also be considered. The value of this parameter is calculated as follows:

$$
\% M A E=\left(\frac{1}{N} \sum_{i}^{N}\left|\frac{T_{i}-P_{i}}{T_{i}}\right|\right) \cdot 100 \% .
$$

In which, $T_{i}$ is the cutting force value when experimenting at $i^{\text {th }}$ experiment; $P_{i}$ is the value of cutting force when predicted at $i^{\text {th }}$ experiment; $N$ is the number of experiments performed, $N=18$. The values of cutting force when predicted by three models are presented in Table $\mathbf{5}$.

Table 5

Values of cutting force when predicting by models

\begin{tabular}{ccccc}
\hline \multirow{2}{*}{ No. } & Experimental Fc $(\mathbf{N})$ & \multicolumn{3}{c}{ Predicted cutting force $\boldsymbol{F}_{\boldsymbol{c}}(\mathbf{N})$} \\
\cline { 3 - 5 } & & Without transformation & Box-Cox transformation & Johnson transformation \\
\hline 1 & 130.56 & 123.3601 & 117.0331 & 115.6442 \\
2 & 110.08 & 110.5067 & 110.1966 & 110.1273 \\
3 & 156.16 & 174.7201 & 150.1596 & 152.0765 \\
4 & 112.64 & 110.5067 & 110.1966 & 110.1273 \\
5 & 85.76 & 92.9601 & 90.6808 & 89.70174 \\
6 & 240.64 & 214.8801 & 188.0776 & 197.8411 \\
7 & 258.56 & 232.1601 & 193.0588 & 201.5439 \\
8 & 152.32 & 185.9201 & 243.3241 & 232.1583 \\
9 & 111.36 & 110.5067 & 110.1966 & 110.1273 \\
10 & 104.96 & 110.5067 & 110.1966 & 110.1273 \\
11 & 92.16 & 58.5601 & 83.3478 & 83.90721 \\
12 & 104.96 & 97.1201 & 97.1332 & 96.40385 \\
13 & 106.24 & 87.6801 & 108.3061 & 107.6719 \\
14 & 92.16 & 117.9201 & 96.7959 & 96.63355 \\
15 & 79.36 & 87.2001 & 83.4638 & 84.02749 \\
16 & 104.96 & 110.5067 & 110.1966 & 110.1273 \\
17 & 119.04 & 110.5067 & 110.1966 & 110.1273 \\
18 & 88.32 & 114.7201 & 92.7159 & 92.93838
\end{tabular}


Table 6 shows the values of $R-S q, R-S q(a d j)$ and $\% M A E$ of three models.

Table 6

Comparison of cutting force models

\begin{tabular}{cccc}
\hline Models & $\boldsymbol{R}-\boldsymbol{S q}$ & $\boldsymbol{R}-\boldsymbol{S q}(\boldsymbol{a d j})$ & $\boldsymbol{\%} \boldsymbol{M A E}$ \\
\hline Without using transformation & 0.8571 & 0.6964 & 12.15 \\
Using Box-Cox transformation & 0.8824 & 0.7500 & 10.10 \\
Using Johnson transformation & 0.8686 & 0.7208 & 9.22
\end{tabular}

From the data in Table 6, it shows that the model without data transformation has $R-S q$, $R-S q(a d j)$ smaller than two models using data transformation. On the other hand, the \% $M A E$ value of the model without using data transformation is also larger than this value of the other two models. Since then, it is confirmed that the model that does not use data transformation has the lowest accuracy. When looking at the two models using the data transformation, it can be seen that the model using the Box-Cox transformation has greater $R-S q$ and $R-S q(a d j)$ coefficients than the model using Johnson transformation. However, the model using the Box-Cox transformation also has a larger \% $\% A E$ parameter than the model using the Johnson transformation. Therefore, if only 3 parameters including $R-S q, R-S q(a d j)$ and \% $M A E$ are considered, it is not confirmed that the model using the transformation has higher accuracy. To solve this problem, two sets of data on cutting force predicted by these two models by $t$-test should be compared. Minitab 16 statistics software is also applied in this case. With the assumption that the cutting force dataset predicted by the Box-Cox transformation model is «not equal» to the cutting force dataset predicted by the Johnson transformation model, the significance level is chosen to be 0.05 . The results of comparing these two datasets are presented in Fig. 8. Information about the comparison results is presented in Table 7.

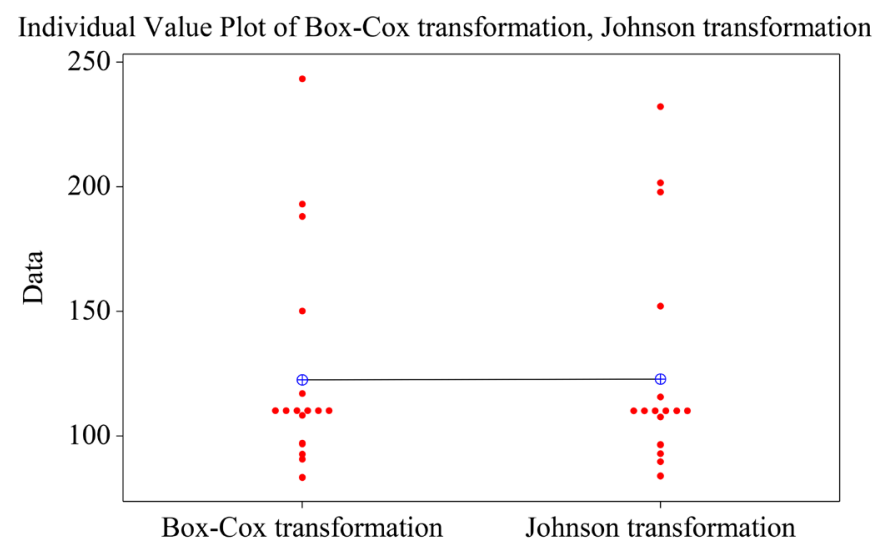

Fig. 8. Individual value plot of Box-Cox transformation, Johnson transformation

Table 7

Two-sample T for Box-Cox transformation and Johnson transformation

\begin{tabular}{ccccc}
\hline Models & N & Mean & StDev & SE Mean \\
\hline Box-Cox transformation & 18 & 122.5 & 43.4 & 10 \\
Johnson transformation & 18 & 122.9 & 43.6 & 10
\end{tabular}

Difference $=m u($ Box-Cox transformation $)-m u($ Johnson transformation $)$.

Estimate for difference: -0.3 .

$95 \%$ CI for difference: $(-29.8,29.2)$.

$\mathrm{T}$-Test of difference $=0($ vs not $=): T-$ Value $=-0.02 ; P-$ Value $=0.982 ; D F=33$ 
From the data in Table 7 shows that the mean values of the two models are very close (122.5 and 122.9). When observing the graph in Fig. 8, this statement is seen more clearly. The standard deviations of the two models are also very close (43.4 and 43.6). The standard error of two models is equal to 10. In particular, $P$-value of 0.982 is much larger than the significance level, the above hypothesis has been rejected and it can be confirmed that the two data sets are equivalent [27]. In other words, the model using the Box-Cox transformation and the model using the Johnson transformation have equal accuracy.

The $\lambda$ value in the Box-Cox transformation found in this study is equal to -2.00 . However, this is a rounded result using Minitab software. In fact, the $\lambda$ value could be a different one, and then the Box-Cox cutting force model will have more accuracy. Thus, the use of Minitab software to determine $\lambda$ values is a limitation of this study. In order to be able to apply the Box-Cox transformation when building a model with a higher precision, it is necessary to specify the exact value of the $\lambda$ (instead of the rounding value, $\lambda=2.00$ ). This work requires a large number of calculations, and will be carried out by the study's authors in the next time.

In addition, the comparison of the model using the Box-Cox transformation and the model using the Johnson transformation is only done by t-test. In order to get more accurate conclusions, it is necessary to compare these two models when using them in predicting cutting force under certain experimental conditions. This content will also be improved in the coming time.

\section{Conclusion}

This study has carried out the experiment of milling SCM440 steel with TiN coated cutting tool with a radius tip of $0.5 \mathrm{~mm}$. Influence of cutting speed, feed rate and cutting depth on the cutting force has been conducted; cutting force model and two data transformations of Box-Cox and Johnson have been used to build two new models of shear force. Some conclusions are drawn as follows:

- among three parameters of cutting parameters including cutting speed, feed rate and cutting depth, feed rate is only parameter that significantly affects the cutting force;

- the cutting force model using the Box-Cox transformation and the cutting force model using the Johnson transformation has equal accuracy, and is more accurate than the model that does not use the data transformation. The standard deviations of the two models (using the Box-Cox transformation and Johnson transformation) are also very close (43.4 and 43.6). The standard error of two models is equal to 10 ;

- Box-Cox and Johnson data transformations have not only succeeded in improving the accuracy of regression models in published documents, but have also succeeded in improving accuracy of the cutting force model in this study. Besides, it also holds promise for success in improving accuracy when used in other studies;

- using three cutting force models built in this study to solve the optimization problem for each case and then comparing with the experimental results are the works that the authors of this article will be conducted in the upcoming time.

\section{Acknowledgement}

The authors would like to send sincere thanks to Hanoi University of industry for their financial support in the implementation of this study.

\section{References}

[1] Budak, E. (2006). Analytical models for high performance milling. Part I: Cutting forces, structural deformations and tolerance integrity. International Journal of Machine Tools and Manufacture, 46 (12-13), 1478-1488. doi: https://doi.org/ 10.1016/j.jimachtools.2005.09.009

[2] Dang, J.-W., Zhang, W.-H., Yang, Y., Wan, M. (2010). Cutting force modeling for flat end milling including bottom edge cutting effect. International Journal of Machine Tools and Manufacture, 50 (11), 986-997. doi: https://doi.org/10.1016/ j.ijmachtools.2010.07.004

[3] Narita, H. (2013). A determination method of cutting coefficients in ball end milling forces model, International journal of Automation Technology, 7 (1), 39-44. 
[4] Gao, G., Wu, B., Zhang, D., Luo, M. (2013). Mechanistic identification of cutting force coefficients in bull-nose milling process. Chinese Journal of Aeronautics, 26 (3), 823-830. doi: https://doi.org/10.1016/j.cja.2013.04.007

[5] Guo, M., Wei, Z., Wang, M., Li, S., Liu, S. (2018). An identification model of cutting force coefficients for five-axis ball-end milling. The International Journal of Advanced Manufacturing Technology, 99 (1-4), 937-949. doi: https://oi.org/10.1007/ s00170-018-2451-6

[6] Wan, M., Zhang, W.-H., Dang, J.-W., Yang, Y. (2010). A novel cutting force modelling method for cylindrical end mill. Applied Mathematical Modelling, 34 (3), 823-836. doi: https://doi.org/10.1016/j.apm.2009.09.012

[7] Šajgalík, M., Kušnerová, M., Harničárová, M., Valíček, J., Czán, A., Czánová, T. et. al. (2020). Analysis and Prediction of the Machining Force Depending on the Parameters of Trochoidal Milling of Hardened Steel. Applied Sciences, 10 (5), 1788. doi: https://doi.org/10.3390/app10051788

[8] Muthusamy Subramanian, A. V., Nachimuthu, M. D. G., Cinnasamy, V. (2017). Assessment of cutting force and surface roughness in LM6/SiC p using response surface methodology. Journal of Applied Research and Technology, 15 (3), $283-296$. doi: https://doi.org/10.1016/j.jart.2017.01.013

[9] Salguero, J., Calamaz, M., Batista, M., Girot, F., Marcos Bárcena, M. (2014). Cutting Forces Prediction in the Dry Slotting of Aluminium Stacks. Materials Science Forum, 797, 47-52. doi: https://oi.org/10.4028/www.scientific.net/msf.797.47

[10] Constantin, C., Constantin, G. (2013). Empirical model of the cutting forces in milling. Proceedings in Manufacturing Systems, 8 (4), 205-212.

[11] Bağci, E. (2017). Experimental investigation of effect of tool path strategies and cutting parameters using acoustic signal in complex surface machining. Journal of Vibroengineering, 19 (7), 5571-5588. doi: https://doi.org/10.21595/jve.2017.18475

[12] Biró, I., Czampa, M., Szalay, T. (2015). Experimental Model for the Main Cutting Force in Face Milling of a High Strength Structural Steel. Periodica Polytechnica Mechanical Engineering, 59 (1), 16-22. doi: https://doi.org/10.3311/ppme.7516

[13] Günay, M., Kaçal, A., Turgut, Y. (2011). Optimization of machining parameters in milling of Ti-6Al-4V alloy using Taguchi method. e-Journal of New World Sciences Academy - Engineering Sciences, 6 (1), 428-440.

[14] Patwari, M. A., Amin, A. K. M. N., Faris, W. F. (1970). Prediction of tangential cutting force in end milling of medium carbon steel by coupling design of experiment and response surface methodology. Journal of Mechanical Engineering, 40 (2), $95-103$. doi: https://doi.org/10.3329/jme.v40i2.5350

[15] Chuangwen, X., Ting, X., Xiangbin, Y., Jilin, Z., Wenli, L., Huaiyuan, L. (2016). Experimental tests and empirical models of the cutting force and surface roughness when cutting 1 Cr13 martensitic stainless steel with a coated carbide tool. Advances in Mechanical Engineering, 8 (10), 168781401667375. doi: https://doi.org/10.1177/1687814016673753

[16] Chen, J.-Y., Chan, T.-C., Lee, B.-Y., Liang, C.-Y. (2020). Prediction model of cutting edge for end mills based on mechanical material properties. The International Journal of Advanced Manufacturing Technology, 107 (7-8), $2939-2951$. doi: https://doi.org/10.1007/s00170-019-04884-8

[17] Arunnath, A., Masooth, P. H. S. (2021). Optimization of process parameters in CNC turning process on machining SCM440 steel by uncoated carbide and TiCN/A12O3/TiN coated carbide tool under dry conditions. Materials Today: Proceedings, 45, 6253-6269. doi: https://doi.org/10.1016/j.matpr.2020.10.699

[18] Thirumalai, R., Srinivas, S., Vinodh, T., Kowshik Kumar, A. L., Kumar, M. K. (2014). Optimization of Surface Roughness and Flank Wear in Turning SCM440 Alloy Steel Using Taguchi Method. Applied Mechanics and Materials, 592-594, 641-646. doi: https://doi.org/10.4028/www.scientific.net/amm.592-594.641

[19] Reddy, N. S. K., Yang, M. (2009). Development of an electro static lubrication system for drilling of SCM 440 steel. Proceedings of the Institution of Mechanical Engineers, Part B: Journal of Engineering Manufacture, 224 (2), $217-224$. doi: https://doi.org/10.1243/09544054jem1670

[20] Basar, G., Kahraman, F. (2018). Modeling and optimization of face milling process parameters for AISI 4140 steel. Tehnički Glasnik, 12 (1), 5-10. doi: https://doi.org/10.31803/tg-20180201124648

[21] Sales, W., Becker, M., Barcellos, C. S., Landre, J., Bonney, J., Ezugwu, E. O. (2009). Tribological behaviour when face milling AISI 4140 steel with minimum quantity fluid application. Industrial Lubrication and Tribology, 61 (2), 84-90. doi: https://doi.org/10.1108/00368790910940400

[22] Stipkovic, M. A., Bordinassi, É. C., Farias, A. de, Delijaicov, S. (2017). Surface Integrity Analysis in Machining of Hardened AISI 4140 Steel. Materials Research, 20 (2), 387-394. doi: https://doi.org/10.1590/1980-5373-mr-2016-0420

[23] Xu, Q., Zhao, J., Ai, X. (2017). Cutting performance of tools made of different materials in the machining of $42 \mathrm{CrMo} 4$ highstrength steel: a comparative study. The International Journal of Advanced Manufacturing Technology, 93 (5-8), $2061-2069$. doi: https://doi.org/10.1007/s00170-017-0666-6

[24] Dean, A., Voss, D., Draguljić, D. (2017). Design and Analysis of Experiments. Springer, 840. doi: https://doi.org/10.1007/ 978-3-319-52250-0 
[25] Trung, D. D. (2020). Influence of Cutting Parameters on Surface Roughness during Milling AISI 1045 Steel. Tribology in Industry, 42 (4), 658-665. doi: https://doi.org/10.24874/ti.969.09.20.11

[26] Dean, A., Voss, D. (Eds.) (1999). Design and Analysis of Experiments. Springer, 742. doi: https://doi.org/10.1007/b97673

[27] Du, N. V., Binh, N. D. (2011). Design of experiment techniques. Science and technics publishing House.

[28] Bhardwaj, B., Kumar, R., Singh, P. K. (2014). An improved surface roughness prediction model using Box-Cox transformation with RSM in end milling of EN 353. Journal of Mechanical Science and Technology, 28 (12), $5149-5157$. doi: https://doi.org/10.1007/s12206-014-0837-4

[29] Bhardwaj, B., Kumar, R., Singh, P. K. (2013). Effect of machining parameters on surface roughness in end milling of AISI 1019 steel. Proceedings of the Institution of Mechanical Engineers, Part B: Journal of Engineering Manufacture, 228 (5), $704-714$. doi: https://doi.org/10.1177/0954405413506417

[30] Nguyen, N.-T., Trung, D. D. (2020). Modeling And Improvement of the Surface Roughness Model in Hole Turning Process $3 \times 13$ Stainless Steel by Using Johnson Transformation. International Journal of Mechanical and Production Engineering Research and Development, 10 (3), 12097-12110. doi: https://doi.org/10.24247/ijmperdjun20201157

[31] Uyen, V. T. N., Son, N. H. (2021). Improving accuracy of surface roughness model while turning 9XC steel using a Titanium Nitride-coated cutting tool with Johnson and Box-Cox transformation. AIMS Materials Science, 8 (1), 1-17. doi: https://doi.org/10.3934/matersci.2021001

[32] Trung, D. D. (2021). Influence of Cutting Parameters on Surface Roughness in Grinding of 65G Steel. Tribology in Industry, 43 (1), 167-176. doi: ttps://doi.org/10.24874/ti.1009.11.20.01

[33] Sakia, R. M. (1992). The Box-Cox Transformation Technique: A Review. The Statistician, 41 (2), 169. doi: https://doi.org/ $10.2307 / 2348250$

Received date 07.04.2021

(C) The Author(s) 2021

Accepted date 10.07.2021

This is an open access article

Published date 13.09.2021 under the Creative Commons CC BY license

How to cite: Thien, N. V., Trung, D. D. (2021). Study on model for cutting force when milling SCM440 steel. EUREKA: Physics and Engineering, 5, 23-35. doi: https://doi.org/10.21303/2461-4262.2021.001743 